\title{
A compensatory base change in human U2 snRNA can suppress a branch site mutation
}

\author{
Yuan Zhuang and Alan M. Weiner ${ }^{1}$ \\ Department of Molecular Biophysics and Biochemistry, Yale University School of Medicine, New Haven, Connecticut 06510 \\ USA
}

\begin{abstract}
We have developed an assay to test whether U2 snRNA can base-pair with the branch site during mammalian mRNA splicing. The $\beta^{110}$ point mutation (GG $\rightarrow$ AG) within the first intron of human $\beta$-globin generates a new $3^{\prime}$ splice site that is preferentially used. We show here that use of the normal 3' splice site can be restored either by improving the match of a cryptic branch site to the branch site consensus or by introducing mutant $U 2$ snRNAs with greater complementarity to the cryptic branch site. These data indicate that human U2 snRNA can form base pairs with the mRNA precursor; however, base pairing appears to be optional because some mammalian branch sites do not match the consensus.
\end{abstract}

[Key Words: U2 snRNA; splicing; branch site]

Received June 20, 1989; revised version accepted August 4, 1989.

The splicing of mRNA precursors is carried out in all eukaryotes by a highly conserved ribonucleoprotein machine, known as the spliceosome, which consists of five distinct small nuclear ribonucleoprotein particles (the $\mathrm{U} 1, \mathrm{U} 2, \mathrm{U} 4, \mathrm{U} 5$, and U6 snRNPs) and a number of auxiliary factors (for a recent review, see Steitz et al. 1988). The U2 snRNA component of the U2 snRNP has been remarkably conserved through evolution, from budding yeast to mammals, and has been shown to be essential for yeast mRNA splicing in vivo (Ares 1986; Igel and Ares 1988; Shuster and Guthrie 1988) and for mammalian mRNA splicing in vitro (Black et al. 1985; Krainer and Maniatis 1985). The suggestion that U2 snRNA might base-pair with the branch site within the intron (Keller and Noon 1984) was supported initially by experiments showing that the mammalian U2 snRNP binds to the branch site during spliceosome assembly in vitro (Chabot et al. 1985; Ruskin et al. 1988). Subsequently, the existence of base-pairing between $\mathrm{U} 2$ and the branch site in yeast was proved by elegant genetic experiments demonstrating that mutations in the invariant yeast branch site UACUAA ${ }^{\star} \mathrm{C}$ (where $A^{*}$ is the branch point residue/ can be suppressed in vivo by compensatory changes in the corresponding GUAGUA sequence of yeast U2 RNA (Parker et al. 1987).

Point mutations in the yeast UACUAAC branch site sequence can have strong effects on splicing (Langford et al. 1984; Parker et al. 1987). In contrast, mammalian branch sites conform only weakly to a PyUPuA ${ }^{\star} \mathrm{C}$ con-

${ }^{1}$ Corresponding author. sensus (Keller and Noon 1984) and can often be mutated or even deleted without major effects on splicing either in vitro or in vivo (Padgett et al. 1985; Hornig et al. 1986; Ruskin et al. 1985). Previously, we and others investigated the sequence requirements for mammalian branch site function by using competition assays that are sensitive to the quality of the branch site (Reed and Maniatis 1988; Zhuang et al. 1989). We found that splicing efficiency depends on the match of the branch site to the PyUPuAC consensus, that the invariant yeast UACUAAC sequence is, in fact, the most efficient mammalian branch site, and that no branch site mutations abolish splicing completely.

Because the GUAGUA element in yeast U2 snRNA that base-pairs with yeast UACUAAC (Parker et al. 1987 ) is conserved from yeast to mammals (Ares 1986), the preceding observations strongly suggest that $\mathrm{U} 2$ snRNA base-pairs with the branch site in mammals as it does in yeast. However, the ability of mammalian splicing to proceed without any credible match to UACUAAC or the weak branch site consensus PyUPuAC raises the possibility that the postulated base-pairing does not occur. Here, we provide direct evidence for base-pairing between U2 snRNA and the branch site in mammals by showing that a mutation in the cryptic branch site of the first intron of human $\beta$-globin gene can be suppressed specifically and efficiently by a mutant U2 snRNA bearing a compensatory base change. Our data show that base-pairing between $\mathrm{U} 2$ and the branch site can facilitate mRNA splicing. Wu and Manley (1989) reached similar conclusions in the accompanying paper. 


\section{Results}

\section{An assay for branch site suppression}

Normal splicing of the first intron of human $\beta$-globin uses a branch site located at position -37 relative to the 3 ' splice site, but deletion of the normal branch site activates a cryptic branch site at position -24 (Ruskin et al. 1985; see Fig. 1). Previously, we found that the cryptic branch site could also be activated by mutations that decrease the quality of the normal branch site or increase the quality of the cryptic branch site; moreover, the quality of each branch site in our assays appeared to reflect its match to UACUAAC and, thus, its potential for base-pairing with the conserved GUAGUA sequence in U2 snRNA (Zhuang et al. 1989). These observations encouraged us to design an in vivo assay, using the first intron of human $\beta$-globin, to test whether mutations in the GUAGUA sequence of U2 snRNA could suppress a mutation in the normal branch site or could activate the cryptic branch site. Unfortunately, use of the normal and cryptic branch sites within the first intron of the unmodified $\beta$-globin gene cannot be distinguished in vivo because the final spliced products are identical. Therefore, we modified the intron by introducing a second 3' splice site between the cryptic branch site and the normal $3^{\prime}$ splice site (Fig. 1B). The result of this mod- ification, as shown below, is that the choice of the normal or cryptic branch site determines which of two alternative $3^{\prime}$ splice sites will be used.

A point mutation from GG to $A G$ was introduced 21 nucleotides upstream from the normal 3 ' splice site of the first intron of human $\beta$-globin (Fig. 1B). This mutation, known as $\beta^{110}$, previously had been shown to generate an efficient alternative $3^{\prime}$ splice site (Busslinger et al. 1981; Fukumaki et al. 1982); in a transient expression assay using HeLa cells, $90 \%$ of the splicing used the $\beta^{110}$ 3 ' splice site and only $10 \%$ used the normal 3 ' splice site (Busslinger et al. 1981). Although the branch site(s) responsible for the observed pattern of $\beta^{110}$ splicing in vivo cannot be determined easily, $\beta^{110}$ splicing has been shown to use the normal branch site in vitro (Reed and Maniatis 1985) in accord with the observation that all branch sites characterized to date lie at least 18 nucleotides upstream from the $3^{\prime}$ splice site (Hartmuth and Barta 1988). Because the cryptic branch site is only $5 \mathrm{nu}^{-}$ cleotides upstream from the $\beta^{110} 3^{\prime}$ splice site, it seemed likely that splicing to the $\beta^{110} 3^{\prime}$ splice site would be unable to use the cryptic branch site. This reasoning suggested that in a $\beta^{110}$ mutant background, use of the cryptic branch site might lead exclusively to splicing at the normal 3' splice site, while use of the normal branch site might be compatible with splicing to either the $\beta^{110}$ or the normal 3' splice site.

(A)

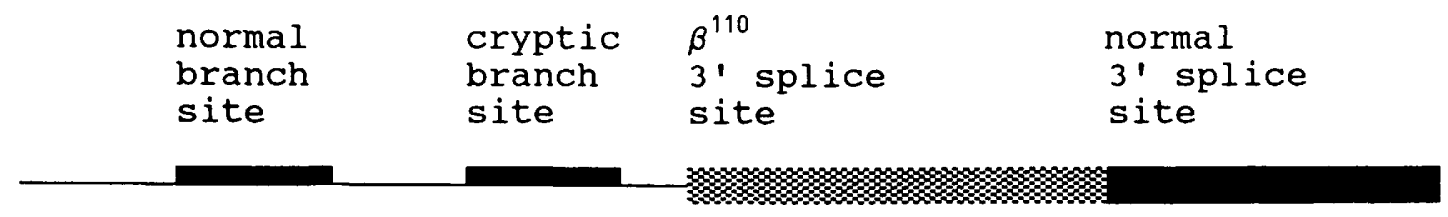

(B)
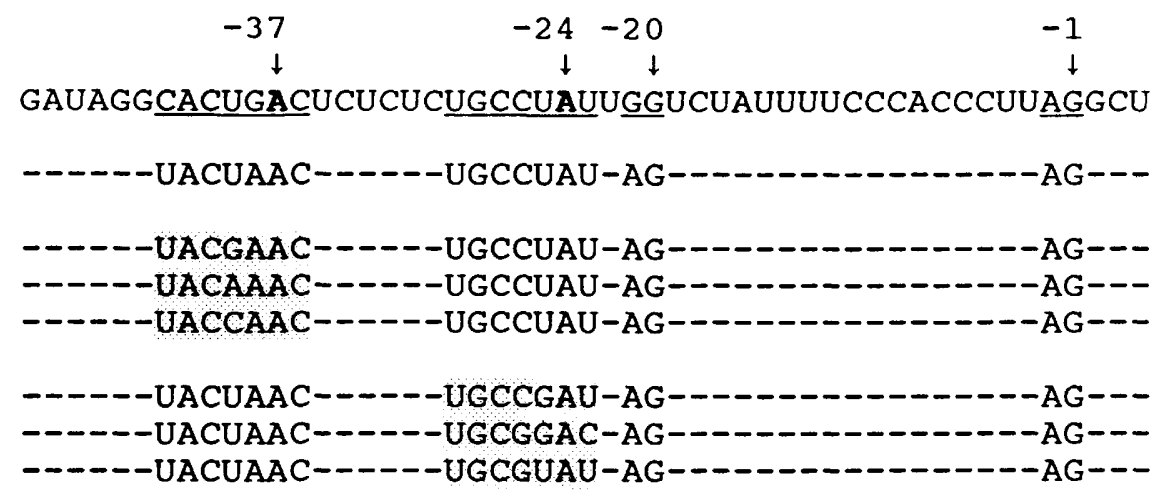

$\beta-g l o b i n$

$10, \beta^{110}$

$13, \beta^{110}$

$14, \beta^{110}$

$15, \beta^{110}$

$10, f, \beta^{110}$
$10, C, \beta^{110}$

$10, g, \beta^{110}$

Figure 1. Structure and sequence of the $3^{\prime}$ end of first intron of the human $\beta$-globin mRNA precursor. $(A)$ Schematic diagram showing the relative positions of two branch sites and two $3^{\prime}$ splice sites on the RNA sequence shown in $B$. $(B)$ Corresponding sequences of the wild-type human $\beta$-globin mRNA precursor (top line) and a variety of mutants used in these experiments (below). Numbers above the wild-type sequence indicate the distances in nucleotides of each branch site and the $\beta^{110} 3^{\prime}$ splice site from the normal 3' splice site. (Right) The name of each mutant is composed of a number designating the mutation at the normal branch site, a letter designating the mutation at the cryptic branch site, and $\beta^{110}$ to indicate the presence of a point mutation from $G$ to $A$ at position -21 (Zhuang et al. 1989). The first set of mutations was made within the normal branch site (lightly shaded) and tested as shown in Fig. 2A; a second set of mutations was made within the cryptic branch site (also lightly shaded) and tested as shown in Fig. 2B. 
To test whether branch site selection affects alternative $3^{\prime}$ splicing of the modified $\beta$-globin introns (Fig. 1B), we introduced the corresponding plasmid constructs into HeLa cells by transfection and assayed the splicing pattern by RNase protection (Fig. 2). To simplify this analysis, we chose as the reference construct ' $10, \beta^{110}$, in which the normal branch site has been mutated to the maximally efficient UACUAAC (Zhuang et al. 1989). We then tested point mutations that disrupted potential complementarity between the normal branch site and U2 (Fig. 2A), as well as point mutations that restored potential complementarity between the cryptic branch site and U2 RNA (Fig. 2B). As judged by $3^{\prime}$ exon protection, both kinds of mutations increased use of the normal $3^{\prime}$ splice site when compared to $10, \beta^{110}$ /Fig. $2 \mathrm{~A}$ and $\mathrm{B}$ ). Consistent with previous evidence that the match to the mammalian PyUPuAC consensus determines the quality of a branch site (Reed and Maniatis 1988; Zhuang et al. 1989), a point mutation at the cryptic branch site from UGCCUAU to UGCGUAU has no effect on alternative $3^{\prime}$ splicing (Fig. 2B, lane g). These results clearly show that branch site selection determines the pattern of alternative $3^{\prime}$ splicing in this construct and that the cryptic branch site controls the use of the normal 3' splice site. Although we have not determined branch site selection directly, we can use these constructs as an assay for the ability of a compensatory mutation in U2 snRNA to suppress a mutation in the normal branch site mutation or to activate the cryptic branch site.

Use of the $\beta^{110} 3^{\prime}$ splice site cannot be restored by suppressing mutations in the normal branch site

First we tried to suppress three different mutations in the normal branch site $\left(13, \beta^{110}, 14, \beta^{110}\right.$, and $\left.15, \beta^{110}\right)$, by making a compensatory base change in the GUAGUA sequence of U2 snRNA. Each of these branch site muta-
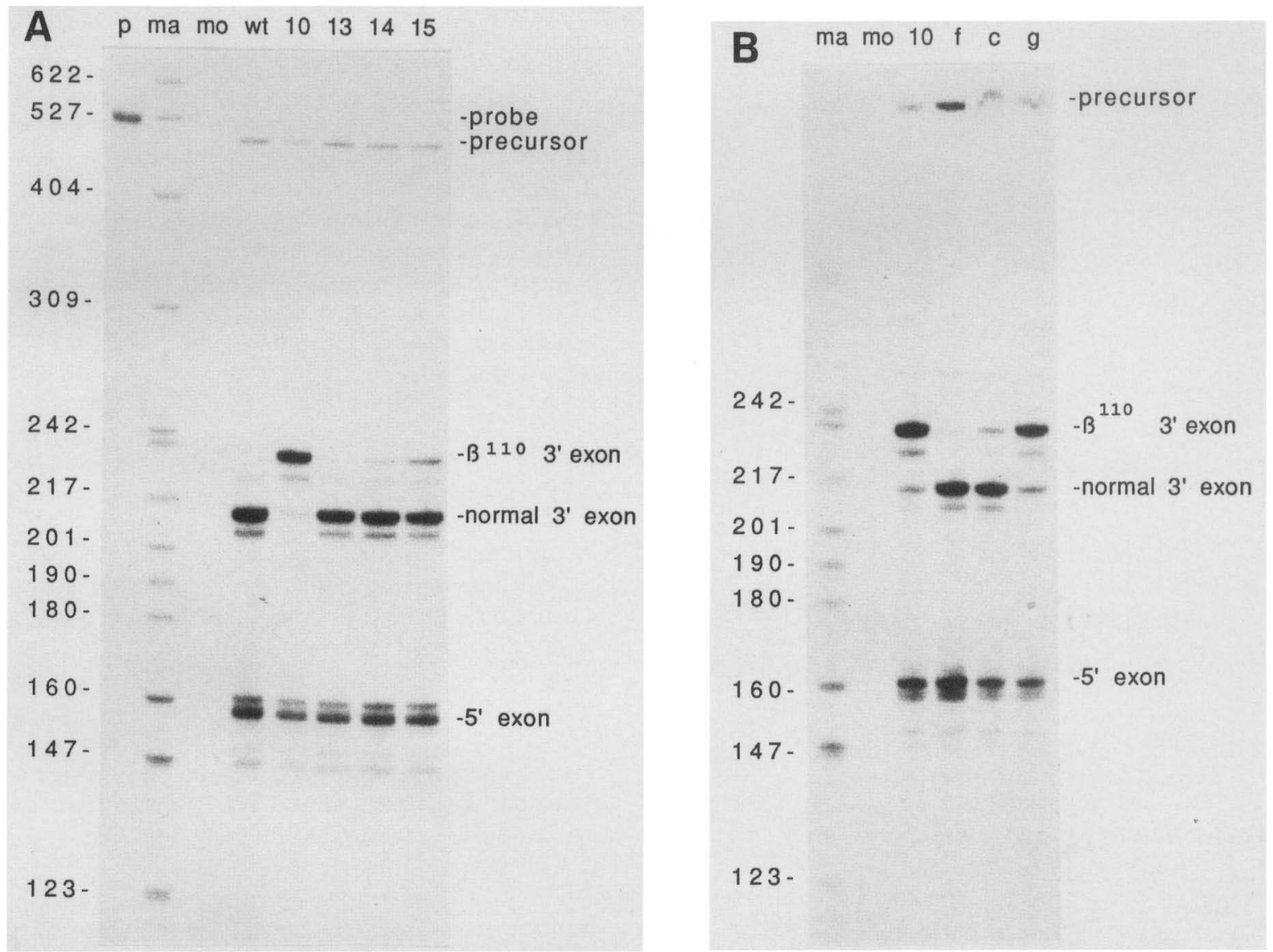

Figure 2. Effect of branch site mutations on alternative $3^{\prime}$ splicing. Plasmid constructs containing the indicated mutations in the first intron of the human $\beta$-globin gene were introduced into HeLa cells by transfection. Stable RNA products were assayed $48 \mathrm{hr}$ later by RNase protection using total cytoplasmic RNA. (A) Test of mutations in the normal branch site. (p) Probe; (ma) DNA size markers prepared by end-labeling a HpaII digest of pBR322 with T4 polynucleotide kinase; (mo) mock transfection without plasmid DNA; (wt) transfection with the wild-type human $\beta$-globin gene; (lanes $10,13,14$, and 15 ) transfection with constructs $10, \beta^{110}, 13, \beta^{110}, 14, \beta^{110}$, $15, \beta^{110}$, respectively. (Right) The positions of the protected precursor, the $\beta^{110} 3^{\prime}$ exon, the normal $3^{\prime}$ exon, and the $5^{\prime}$ exon; (left) marker sizes. The protected $3^{\prime}$ exon of the wild-type $\beta$-globin is 1 nucleotide shorter than others, as a result of minor differences in the cloning strategy (see Materials and methods). $(B)$ Test of mutations in the cryptic branch site. (Lanes $f, c$, and $g$ ) Transfection with constructs $10, \mathrm{f}, \beta^{110}, 10, \mathrm{c}, \beta^{110}, 10, \mathrm{~g}, \beta^{110}$, respectively. Other lanes are labeled as in $A$. 
tions disrupted the highly conserved fourth position of the UACUAAC sequence (Fig. 1B) and all had a severe effect on the use of the $\beta^{110} 3^{\prime}$ splice site (Fig. 2A). We hoped to restore use of the $\beta^{110} 3^{\prime}$ splice site when the U2-35c gene (encoding human U2 snRNA with a point mutation from $A$ to $C$ at nucleotide 35 ) was cotransfected with $13, \beta^{110}$, when the U2-35t gene was cotransfected with $14, \beta^{110}$, or when the U2-35g gene was cotransfected with $15, \beta^{110}$ (Fig. 3 , bottom). No detectable suppression was observed (Fig. 3), however, and we do not understand why (but see Discussion).

Although mutations in the normal branch site could not be suppressed, we were surprised to find that use of normal $3^{\prime}$ splice site relative to the $\beta^{110} 3^{\prime}$ splice site was increased consistently in cotransfections with the U2-35g gene (Fig. 3, lanes $35 \mathrm{~g}$ ). This led us to consider the possibility that the U2-35g snRNA might favor use of the normal 3 ' splice site by base-pairing preferentially with the cryptic branch site. In fact, the cryptic branch site sequence UGCCUAU has the potential to form an

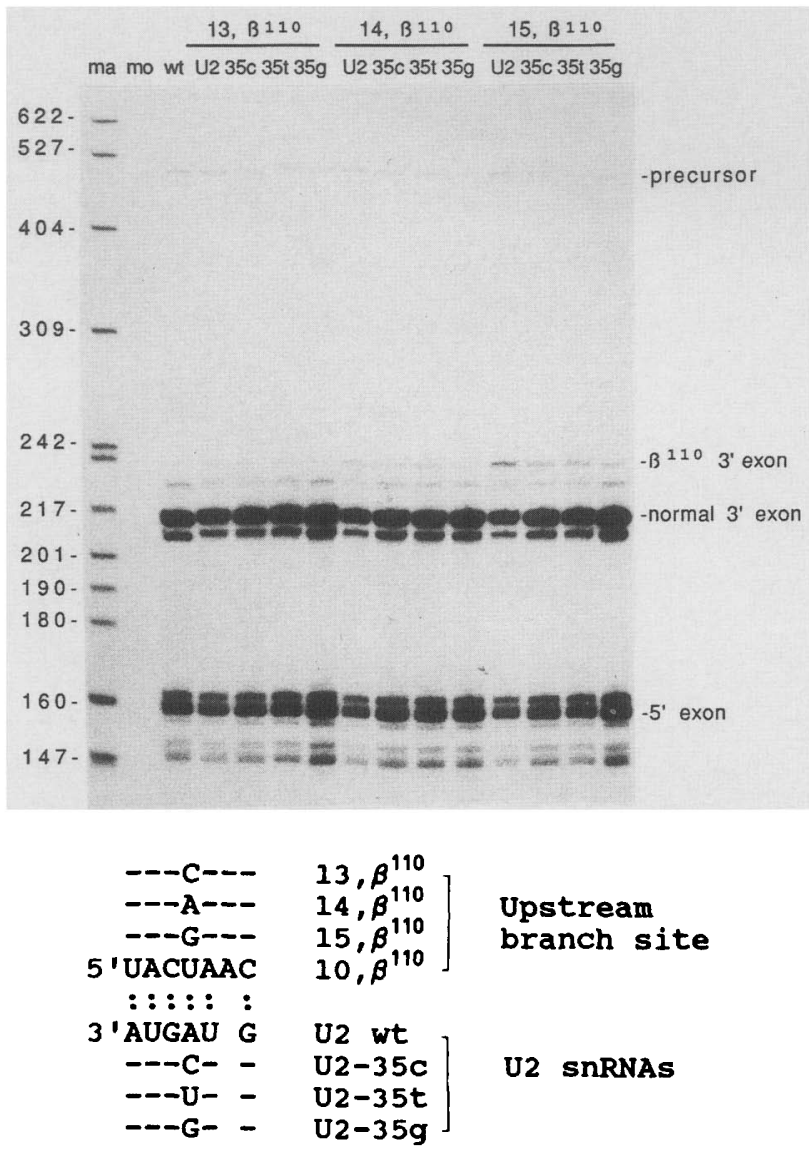

Figure 3. Assay for suppression of mutations in the normal branch site. Constructs containing the $\beta$-globin mutations $13, \beta^{110}, 14, \beta^{110}$, and $15, \beta^{110}$ were cotransfected into HeLa cells together with the wild-type U2, U2-35c, U2-35t, or U2-35g gene. Markers, control transfections, and the assay for stable spliced products are as in Fig. 2. (Bottom) The proposed basepairing between the mutated branch sites and the mutant U2 snRNAs. additional base pair with the U2-35g snRNA as compared with wild-type $U 2$ (the position of the additional base pair is underlined). This observation encouraged us to test whether mutations in the cryptic branch could be suppressed, although mutations in the normal branch site could not.

\section{Use of the normal $3^{\prime}$ splice site can be restored efficiently by activating the cryptic branch site}

A $\beta$-globin construct containing the $10, \beta^{110}$ mutation was cotransfected into HeLa cells, together with a wildtype U2, U2-35c, U2-35t, or U2-35g gene, and the stable spliced products were assayed by RNase protection (Fig. 4A). Cotransfection with the U2-35g gene increased use of the normal 3' splice site from $<5 \%$ to $>50 \%$ (Fig. 4A), whereas cotransfections with the noncompensatory $\mathrm{U} 2-35 \mathrm{c}$ and U2-35t genes had relatively little effect. This result strongly suggests that base pairing between U2-35g snRNA and the cryptic branch site (Fig. 4A, bottom) is responsible for the suppression. The low level of apparent suppression observed with U2-35c and U2-35t appears to reflect the ability of mutant U2 snRNAs to interfere with use of the normal branch site (see Discussion).

To confirm that base pairing between U2 and the branch site was responsible for the observed suppression, we attempted to suppress a different mutation in the cryptic branch site. The $10, \mathrm{~g}, \beta^{110}$ mutation introduces a different nonconsensus base at the cryptic branch site position suppressed by U2-35g. As expected, the $10, g, \beta^{110}$ mutant branch site was efficiently suppressed by the U2-35c snRNA but not by U2-35t or U2-35g (Fig. 4B).

\section{Mutant U2 genes are expressed in transfected HeLa cells}

To exclude the possibility that the effects of the mutant U2 snRNAs reflect differential expression rather than specific base pairing with the cryptic branch site, we assayed the abundance of the mutant U2 snRNAs by primer extension. A synthetic $\mathrm{U} 2_{38-52}$ primer complementary to positions $38-52$ in U2 RNA (where the first transcribed nucleotide of $\mathrm{U} 2$ is designated position 1) was labeled at the $5^{\prime}$ end with T4 polynucleotide kinase, annealed with the same RNA preparations used in Figure 4, and extended with avian myeloblastosis virus (AMV) reverse transcriptase in the presence of dATP, dGTP, dCTP, and ddTTP. As expected, reverse transcription stops in the presence of ddTTP at position 35 on a wild-type U2 RNA template and at position 30 on all three mutant U2 templates (Fig. 5). Assuming that $20-40 \%$ of the HeLa cells were transfected, we estimate by densitometry that transfected cells contain between 5 and $30 \%$ mutant $U 2$ and that expression of the three different mutants does not vary by more than twofold. These expression levels are comparable to those obtained previously using an internally marked U2 gene (Mangin et al. 1986). 

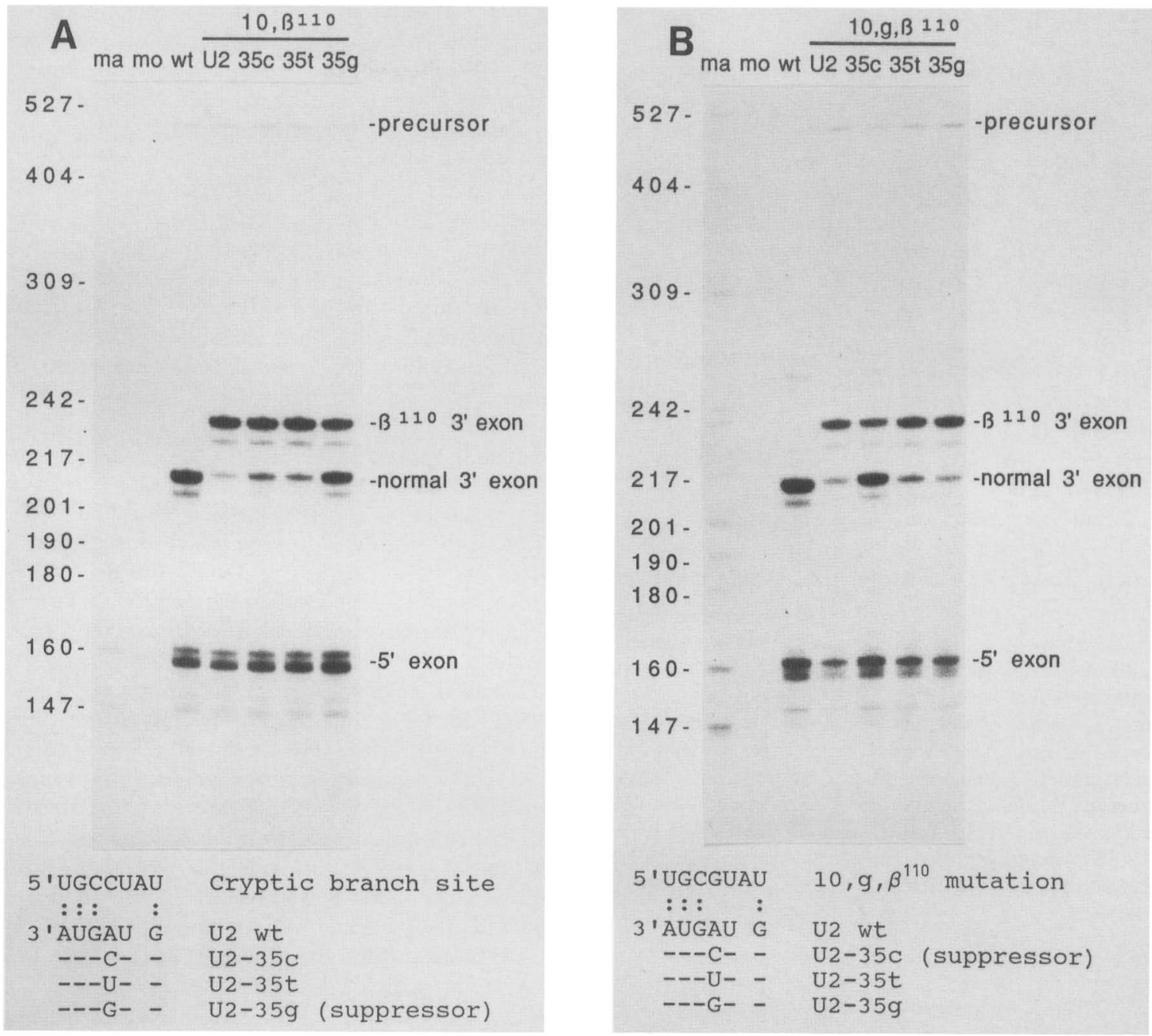

Figure 4. Assay for suppression of mutations in the cryptic branch site. $(A)$ A construct containing the $\beta$-globin mutation $10, \beta^{110}$ was cotransfected into HeLa cells with the wild-type U2, U2-35c, U2-35t, or U2-35g gene. Markers, control transfections, and the assay for stable spliced products are as in Fig. 2. (Bottom) The proposed base-pairing between the cryptic branch site and the mutant U2 RNAs. $(B)$ Suppression of the $\beta$-globin mutation $10, g, \beta^{110}$ was assayed as in $A$.

\section{Discussion}

Using a specially designed construct with two branch sites and two $3^{\prime}$ splice sites within a single intron (Fig. 1), we have been able to show that a cryptic branch site can be activated by mutations in human U2 snRNA which increase the potential for base-pairing with the branch site. These results provide genetic evidence that the U2 snRNP can recognize the branch site in mRNA precursors through base-pairing, as proposed originally by Keller and Noon (1984) and as proved subsequently in the case of budding yeast (Parker et al. 1987). Base pairing between mammalian $\mathrm{U} 2$ and the branch site helps to explain why much of the U2 snRNA sequence has been highly conserved through evolution (Ares 1986; Igel and Ares 1988; Shuster and Guthrie 1988) and supports the emerging view that the mechanism of mRNA splicing is fundamentally similar in mammals and yeast. Although our assay demonstrates that U2 snRNA can form base pairs with the branch site, the success of the assay depends on the observation that the quality of this base pairing is not the only determinant of branch site selection. Branch site selection is also subject to a strong distance constraint that favors the potential branch site nearest to the $3^{\prime}$ splice site but no closer than $\sim 18 \mathrm{nu}-$ cleotides (Hartmuth and Barta 1988). In our assay, the distance constraint guarantees that use of the normal and cryptic branch sites are correlated, respectively, with use of the $\beta^{110}$ and normal $3^{\prime}$ splice sites. The distance constraint may also explain why the cryptic branch site appears to be used even when the normal branch site has greater complementarity to $\mathrm{U} 2$ snRNA (Fig. 2A; cf. lanes 13, 14, and 15 with lane 10).

We do not understand why we were able to suppress mutations in the cryptic branch site (Fig. 4A and B) but not in the normal branch site (Fig. 3). Our failure to suppress mutations in the normal branch site cannot be explained by the effect of the compensatory mutations in 


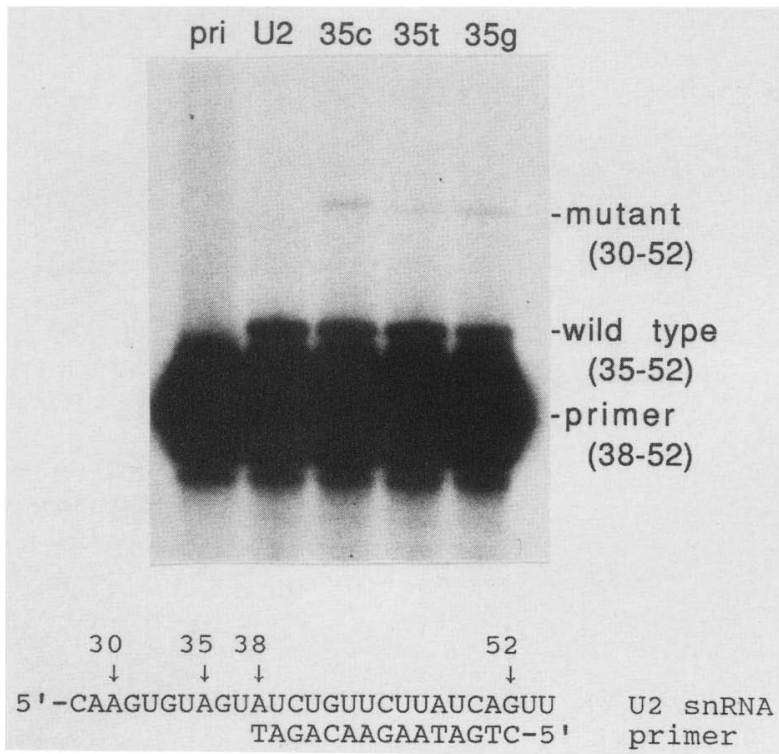

Figure 5. Primer-extension assay for expression of mutant U2 snRNAs in transfected HeLa cells. Primer extensions were performed on the same RNA preparations used in Fig. 4A. (Bottom) The position of the $5^{\prime}$-end-labeled deoxyribooligonucleotide primer on a wild-type U2 snRNA template. Arrows above the U2 sequence indicate the 3 ' ends of the primer extension products generated by AMV reverse transcriptase, using a wildtype or mutant U2 snRNA template in the presence of dATP, dGTP, dCTP, and ddTTP. (Top) U2 snRNA preparations used for primer extension; (right) extension products corresponding to wild-type and mutant U2 snRNA.

U2 snRNA on snRNA transport, snRNP assembly, or altered interactions of the U2 snRNP with other spliceosomal factors, because the same U2 snRNAs that activate the cryptic branch site (Fig. 4A, U2-35g) or suppress a mutation in the cryptic branch site (Fig. 4B, U2-35c) do not suppress a mutation at the normal branch site (Fig. 3 ). Thus, the activity of a suppressor U2 may also reflect steric hindrance between spliceosomal factors or contextual effects unique to the mRNA precursor.

The ability of human U2 to base-pair with the branch site makes it all the more difficult to understand why the mammalian branch site consensus PyUPuAC is so weak (Hartmuth and Barta 1988) compared to the nearly invariant UACUAAC sequence in budding yeast. The simplest interpretation is that base-pairing between U2 and the branch site is obligatory in yeast but optional in mammals, perhaps because branch site selection in mammals is influenced by additional factors that recognize other elements of the intron such as the polypyrimidine tract or the $3^{\prime}$ splice site. An alternative interpretation is that UACUAAC is nearly invariant in yeast because the branch site in yeast, but not in mammals, also interacts with other factors such as the U1 snRNP (Ruby and Abelson 1988; Seraphin et al. 1988; Zillman et al. 1987 1988). However, neither of these interpretations is easy to reconcile with the observation that UACUAAC mutants in budding yeast can have weak phe- notypes or none at all (C. Guthrie, pers. comm.).

Previously we used an mRNA precursor with duplicated $5^{\prime}$ splice sites to demonstrate that a compensatory base change in U1 snRNA would efficiently suppress a $5^{\prime}$ splice site mutation even though the suppressor U1 accounted for no more than $20 \%$ of total U1 (Zhuang and Weiner 1986). In an analogous precursor with duplicated 3' splice sites, however, compensatory base changes in U2 snRNA failed to suppress branch site mutations, although the potential suppressor U2 was no less abundant than the suppressor $\mathrm{U} 1$ in the earlier experiments (Zhuang et al. 1989). Why did the straightforward assay for a suppressor U1 succeed while the analogous assay for a suppressor U2 failed? The U1 snRNP appears to recognize the $5^{\prime}$ splice site directly (Mount et al. 1983), presumably through base-pairing (Zhuang and Weiner 1986). If the initial binding of Ul to the 5' splice site is reversible, a suppressor U1 would be likely to bind more tightly than wild-type Ul to the mutant $5^{\prime}$ splice site, and thus a minority population of suppressor U1 snRNPs could have a disproportionate effect on the pattern of alternative splicing. In contrast to Ul recognition of the $5^{\prime}$ splice site, recognition of the branch site by the U2 snRNP is thought to occur after the U2 snRNP has bound to the precursor and become committed to spliceosome formation (Frendewey et al. 1987; Ruskin et al. 1988). As a result, the wild-type and suppressor U2 snRNPs will have an equal probability of participating in spliceosome formation regardless of subsequent branch site selection, and the pattern of alternative splicing mediated by wild-type U2 will tend to obscure the effects of a minority of suppressor U2 snRNPs.

We were surprised to find that in the case of $10, g, \beta^{110}$, the suppressor U2-35c increased use of the normal $3^{\prime}$ splice site from $<10 \%$ to $\sim 80 \%$ (Fig. $4 \mathrm{~B}$ ), although the suppressor U2 represented, at most, $30 \%$ of the total U2 in the transfected cell, as judged by primer extension (Fig. 5). The explanation may lie in the kinetics of alternative splicing: The branch site mutation analysis (Fig. 2) shows that there is direct competition between splicing to the $\beta^{110}$ and the normal 3' splice site. Moreover, at least in vitro, splicing to the $\beta^{110} 3^{\prime}$ splice site is very slow compared to splicing to the normal $3^{\prime}$ splice site (data not shown). Thus, it is possible that the disparity in reaction rates can augment the effect of the suppressor U2 on splicing to the normal 3' splice site. Similar kinetic arguments may explain why the same suppressor U2 snRNA that activated the cryptic branch site (Fig. 4) failed to suppress mutations in the normal branch site (Fig. 3).

Noncompensatory mutants of $\mathrm{U} 2$ induce a small, but reproducible, increase in use of the cryptic branch site (Fig. 4A and B). This is likely to reflect a decrease in binding of these mutant U2 snRNPs to the normal branch site rather than bona fide suppression at the cryptic branch site. In fact, mutations at position 35 in the noncompensatory U2 snRNAs reduce complementarity to the normal branch site (UACUAAC, in this case) but do not affect potential base pairing with the cryptic branch site. 
For example, U2-35g has no effect on use of the cryptic branch site in the $10, g, \beta^{110}$ assay (Fig. 4B) as might be expected because this $U 2$ mutation only changes an $A_{35}$ : $U$ base pair to $\mathrm{C}_{35}$ : $\mathrm{U}$ base pair during recognition of the normal branch site. The same kind of argument may explain why U2-35c appears to be a stronger suppressor than U2-35g (cf. Fig. 4A and B). Both suppressors form the same base pair $\left(C_{35}: G\right.$ or $\left.G_{35}: C\right)$ when recognizing the cryptic branch site; however, if U2-35c does not recognize the normal branch site as well as U2-35g, U2-35c may use the cryptic branch site preferentially and thus appear to be the stronger suppressor.

The assay described here should facilitate genetic analysis of the role of U2 snRNA in mammalian mRNA splicing. In particular, our ability to assay for the activity of a transfected suppressor U2 gene over a background of endogenous wild-type U2 should enable us to carry out a second site reversion analysis designed to determine what features of U2 snRNA primary and secondary structure are required for suppressor activity. An analogous genetic dissection of a suppressor U1 snRNA (Zhuang and Weiner 1986) is now in progress (Yuo and Weiner 1989). We are especially interested in understanding why the mammalian branch site consensus PyUPuAC is so weak (Hartmuth and Barta 1988) and why natural branch sites can sometimes be deleted with impunity (Hornig et al. 1986; Ruskin et al. 1985). Branch site selection is known to involve many factors other than the U2 snRNP, including proteins /Gerke and Steitz 1986; Tazi et al. 1986; Krämer 1988; Ruskin et al. 1988; Swanson and Dreyfuss 1988), intron sequences between the branch site and the 3' splice site (Archibald et al. 1986; Fu et al. 1988; Smith and Nadal-Ginard 1989), and factors governing selection of the $5^{\prime}$ splice site (Noble et al. 1988; Zillman et al. 1987 1988; Ulfendahl et al. 1989; Ruby and Abelson 1988; Seraphin et al. 1988). Although in vivo studies may prove useful in sorting out the interrelationships between these factors and the U2 snRNP, we hope to develop an assay for in vitro suppression because this would enable us to analyze intermediate steps of spliceosome assembly.

\section{Materials and methods}

\section{Cloning and mutagenesis}

The HindIII-PstI fragment from pSP64-H $\beta \Delta 6$ (Krainer et al. 1984) was subcloned into mp19. Site-directed mutagenesis was performed according to Kunkel (1985), and mutations were confirmed by DNA sequencing. Plasmids for transfection were constructed by replacing the large $\mathrm{T}$ structural gene (from HindIII to PstI) in an SV40 expression vector (Zhuang et al. 1987) with the $\beta$-globin sequence. The control plasmid with a wildtype $\beta$-globin gene was constructed by inserting the HindIIIBamHI fragment of pSP64-H $\beta \Delta 6$ between the HindIII and BclI sites of the SV40 expression vector (Zhuang et al. 1989). The HindIII-BamHI fragment of the $\beta$-globin gene was also subcloned into the pGEM-blue vector (from Promega) for generating the antisense probe.

The human U2 snRNA gene contained the entire U2 snRNA coding region, together with 556 nucleotide of $5^{\prime}$ - and $91 \mathrm{nu}-$ cleotide of 3 '-flanking sequence, and was cloned into mp8 (Yuo et al. 1985). Point mutations were generated and verified as described above. Plasmids for transfection were constructed by recloning the $\mathrm{U} 2$ genes into a $\mathrm{pUCl} 3$ vector.

\section{Transfections and RNase protection assays}

Transfections and RNase protection assays were performed as described (Zhuang and Weiner 1986). For transfections of HeLa cells, a total of $8 \mu \mathrm{g}$ of plasmid DNA per $60-\mathrm{mm}$ plate for $4 \mu \mathrm{g}$ of each plasmid in cotransfections) was used. RNA was prepared by lysis with NP-40, and $10 \%$ of each RNA preparation was used per assay. RNase protection assays were performed with antisense probes made by $\mathrm{T} 7$ transcription from the HindIII$B a m H I$ fragment of the $\beta$-globin gene in the corresponding pGEM-blue vectors. Hybridization and ribonuclease digestion conditions were as described (Melton et al. 1984), except that the digestion was performed with $25 \mathrm{U} / \mathrm{ml}$ of ribonuclease $\mathrm{T} 1$ (CalBiochem) and no ribonuclease A. Protected RNA fragments were resolved on a denaturing $5 \%$ polyacrylamide gel.

\section{Primer extensions}

Primer extensions were performed with AMV reverse transcriptase in the presence of $0.1 \mathrm{~mm}$ each of dATP, dGTP, dCTP, and ddTTP, as described by Montzka and Steitz (1988), except that $25 \mu \mathrm{g} / \mathrm{ml}$ of actinomycin D was included in the reaction. The primer-extension products were resolved on a denaturing $15 \%$ polyacrylamide gel.

\section{Acknowledgments}

We thank Robert Ach for many helpful suggestions regarding the manuscript, and the National Intitutes of Health for support.

\section{References}

Archibald, A.L., N.A. Thompson, and S. Kvist. 1986. A single nucleotide difference at the $3^{\prime}$ end of an intron causes differential splicing of two histocompatibility genes. EMBO $/$. 5: 975-965.

Ares, M., Jr. 1986. U2 RNA from yeast is unexpectedly large and contains homology to vertebrate U4, U5, and U6 small nuclear RNAs. Cell 47: 49-59.

Black, D.L., B. Chabot, and J.A. Steitz. 1985. U2 as well as U1 small nuclear ribonucleoproteins are involved in pre-mRNA splicing. Cell 42: 737-750.

Busslinger, M., N. Moschonas, and R.A. Flavell. 1981. $\beta^{+}$thalassemia: Aberrant splicing results from a single point mutation in an intron. Cell 27: 289-298.

Chabot, B., D.L. Black, D.M. LeMaster, and J.A. Steitz. 1985. The $3^{\prime}$ splice site of pre-messenger RNA is recognized by a small nuclear ribonucleoprotein. Science 230: 1344-1349.

Frendewey, D., A. Krämer, and W. Keller. 1987. Different small nuclear ribonucleoprotein particles are involved in different steps of splicing complex formation. Cold Spring Harbor Symp. Quant. Biol. 52: 287-298.

Fu, X.-Y., H. Ge, and J.L. Manley. 1988. The role of polypyrimidine stretch at the SV40 early pre-mRNA 3 ' splice site in alternative splicing. EMBO \%. 7: 809-817.

Fukumaki, Y., P.K. Ghosh, E.J. Benz Jr., V.B. Reddy, P. Lebowitz, B.G. Forget, and S.M. Weissman. 1982. Abnormally spliced messenger RNA in erythroid cells from patients with $\beta^{+}$thalassemia and monkey cells expressing a cloned $\beta^{+}$-thalassemic gene. Cell 28: 585-593. 
Gerke, V. and J.A. Steitz. 1986. A protein associated with small nuclear ribonucleoprotein particles recognizes the $3^{\prime}$ splice site of premessenger RNA. Cell 47: 973-986.

Hartmuth, K. and A. Barta. 1988. Unusual branch point selection in processing of human growth hormone pre-mRNA. Mol. Cell. Biol. 8: 2011-2020.

Hornig, H., M. Aebi, and C. Weissmann. 1986. Effect of mutations at the lariat branch acceptor site on $\beta$-globin premRNA splicing in vitro. Nature 324: 589-591.

Igel, A.H. and M. Ares Jr. 1988. Internal sequences that distinguish yeast from metazoan U2 snRNA are unnecessary for pre- mRNA splicing. Nature 334: 450-453.

Keller, E.B. and W.A. Noon. 1984. Intron splicing: A conserved internal signal in introns of animal pre-mRNAs. Proc. Natl. Acad. Sci. 81: 7417-7420.

Krainer, A.R., T. Maniatis, B. Ruskin, and M.R. Green. 1984. Normal and mutant human $\beta$-globin pre-mRNAs are faithfully and efficiently spliced in vitro. Cell 36: 993-1005.

Krainer, A.R. and T. Maniatis. 1985. Multiple factors including the small nuclear ribonucleoproteins $U 1$ and $U 2$ are necessary for pre-mRNA splicing. Cell 42: 725-736.

Krämer, A. 1988. Presplicing complex formation requires two proteins and U2 snRNP. Genes Dev. 2: 1155-1167.

Kunkel, T.A. 1985. Rapid and efficient site-specific mutagenesis without phenotypic selection. Proc. Natl. Acad. Sci. 82: $488-492$.

Langford, C.J., F.J. Klinz, C. Donath, and D. Gallwitz. 1984. Point mutations identify the conserved, intron-contained TACTAAC box as an essential splicing sequence in yeast. Cell 36: 645-653.

Mangin, M., M. Ares Jr., and A.M. Weiner. 1986. Human U2 small nuclear RNA genes contain an upstream enhancer. EMBO I. 5: 987-995.

Melton, D.A., P.A. Krieg, M.R. Rebagliati, T. Maniatis, K. Zinn, and M.R. Green. 1984. Efficient in vitro synthesis of biologically active RNA and RNA hybridization probes from plasmids containing a bacteriophage SP6 promoter. Nucleic Acids Res. 12: 7035-7056.

Montzka, K.A. and J.A. Stietz. 1988. Additional low-abundance human small nuclear ribonucleoproteins: U11, U12, etc. Proc. Natl. Acad. Sci. 85: 8885-8889.

Mount, S.M., I. Pettersson, M. Hinterberger, A. Karmas, and J.A. Steitz. 1983. The U1 small nuclear RNA-protein complex selectively binds a $5^{\prime}$ splice site in vitro. Cell 33: 509518.

Noble, J.S.C., C. Prives, and J.L. Manley. 1988. Alternative splicing of SV40 early pre-mRNA is determined by branch site selection. Genes Dev. 2: 1460-1475.

Padgett, R.A., M.M. Konarska, M. Aebi, H. Hornig, C. Weissmann, and P.A. Sharp. 1985. Non-consensus branch-site sequences in the in vitro splicing of transcripts of rabbit $\beta$ globin genes. Proc. Natl. Acad. Sci. 82: 8349-8353.

Parker, R., P.G. Siliciano, and C. Guthrie. 1987. Recognition of the TACTAAC box during mRNA splicing in yeast involves base pairing to the U2-like snRNA. Cell 49: 229-239.

Reed, R. and T. Maniatis. 1985 Intron sequences involved in lariat formation during pre-mRNA splicing. Cell 41: 95105.

-1988. The role of the mammalian branchpoint sequence in pre-mRNA splicing. Genes Dev. 2: 1268-1276.

Ruby, S.W. and J. Abelson. 1988. An early hierarchic role of U1 small nuclear ribonucleoprotein in spliceosome assembly. Science 242: 1028-1035.

Ruskin, B., J.M. Greene, and M.R. Green. 1985. Cryptic branch point activation allows accurate in vitro splicing of human $\beta$-globin intron mutants. Cell 41: 833-844.
Ruskin, B., P.D. Zamore, and M.R. Green. 1988. A factor, $\mathrm{U} 2 \mathrm{AF}$, is required for $\mathrm{U} 2$ snRNP binding and splicing complex assembly. Cell 52: 207-219.

Seraphin, B., L. Kretzner, and M. Rosbash. 1988. A U1 snRNA:pre-mRNA base pairing interaction is required early in yeast spliceosome assembly but does not uniquely define the $5^{\prime}$ cleavage site. EMBO $/$. 7: 2533-2538.

Shuster, E.O. and C. Guthrie. 1988. Two conserved domains of yeast U2 snRNA are separated by 945 nonessential nucleotides. Cell 55: 41-48.

Smith, C.W.J. and B. Nadal-Ginard. 1989. Mutually exclusive splicing of $\alpha$-tropomyosin exons enforced by an unusual lariat branch point location: Implications for constitutive splicing. Cell 56: 749-758.

Steitz, J.A., D.L. Black, V. Gerke, K. Parker, A. Krämer, D. Frendewey, and W. Keller 1988. Functions of abundant UsnRNPs. In Structure and function of major and minor snRNPs (ed. M.L. Birnstiel), pp. 115-154. Springer-Verlag, Heidelberg.

Swanson, M.S. and G. Dreyfuss. 1988. RNA binding specificity of hnRNP proteins: a subset bind to the $3^{\prime}$ end of intron. EMBO I. 7: 3519-3529.

Tazi, J., C. Alibert, J. Temsamani, I. Reveillaud, G. Cathala, C. Brunel, C. and P. Jeanteur. 1986. A protein that specifically recognizes the $3^{\prime}$ splice site of mammalian pre-mRNA introns is associated with a small nuclear ribonucleoprotein. Cell 47: 755-766.

Ulfendahl, P.J., J.-P. Kreivi, and G. Akusjärvi. 1989. Role of the branch site/3'-splice site region in adenovirus-2 E1A premRNA alternative splicing: Evidence for $5^{\prime}$ - and $3{ }^{\prime}$-splice site co-operation. Nucleic Acids Res. 17: 925-938.

Wu, J. and J.L. Manley. 1989. Mammalian pre-mRNA branch site selection by U2 snRNP involves base pairing. Genes Dev. 3: 1553-1561.

Yuo, C.-Y. and A.M. Weiner. 1989. Genetic analysis of the role of human Ul snRNA in mRNA splicing: I. Effect of mutations in the highly conserved stem-loop I of U1. Genes Dev. 3: $697-707$.

Yuo, C., M. Ares Jr., and A.M. Weiner. 1985. Sequences required for $3^{\prime}$ end formation of human $\mathrm{U} 2$ small nuclear RNA. Cell 42: 193-202.

Zhuang, Y. and A.M. Weiner. 1986. A compensatory base change in U1 snRNA suppresses a $5^{\prime}$ splice site mutation. Cell 46: 827-835.

Zhuang, Y., A.M. Goldstein, and A.M. Weiner. 1989. UACUAAC is the preferred branch site for mammalian mRNA splicing. Proc. Natl. Acad. Sci. (in press).

Zhuang, Y., H. Leung, and A.M. Weiner. 1987. The natural 5' splice site of simian virus 40 large $\mathrm{T}$ antigen can be improved by increasing the base complementarity to $\mathrm{Ul}$ snRNA. Mol. Cell. Biol. 7: 3018-3020.

Zillmann, M., S.D. Rose, and S.M. Berget. 1987. Ul small nuclear ribonucleoproteins are required early during spliceosome assembly. Mol. Cell. Biol. 7: 2877-2883.

Zillmann, M., M.L. Zapp, and S.M. Berget. 1988. Gel electrophoretic isolation of splicing complexes containing $\mathrm{U} 1$ small nuclear ribonucleotprotein particles. Mol. Cell. Biol. 8: $814-821$. 


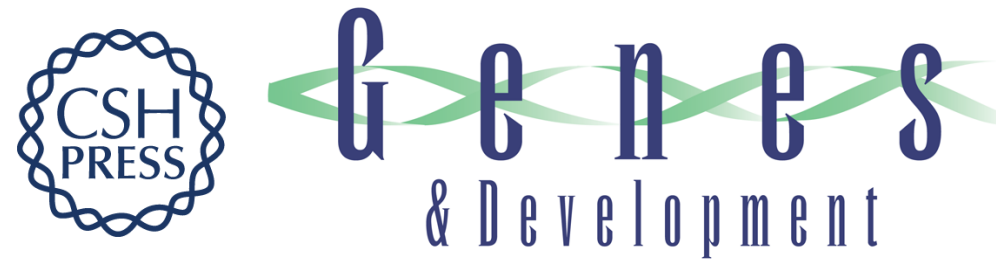

\section{A compensatory base change in human U2 snRNA can suppress a branch site mutation.}

$Y$ Zhuang and $A M$ Weiner

Genes Dev. 1989, 3:

Access the most recent version at doi:10.1101/gad.3.10.1545

References This article cites 43 articles, 16 of which can be accessed free at:

http://genesdev.cshlp.org/content/3/10/1545.full.html\#ref-list-1

License

Email Alerting

Service

Receive free email alerts when new articles cite this article - sign up in the box at the top right corner of the article or click here.

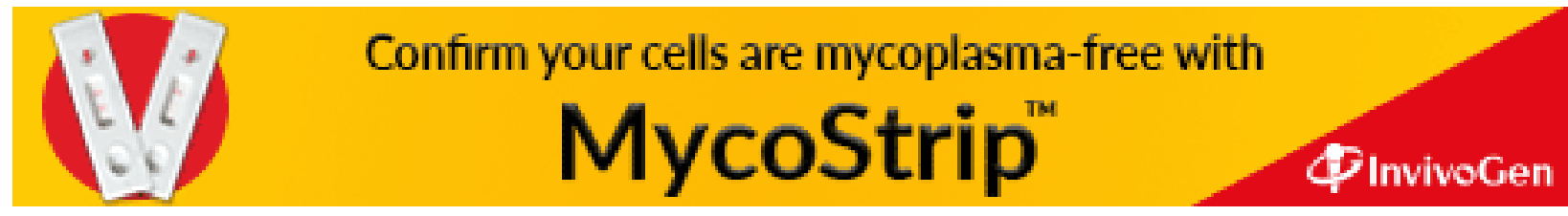

